Prosiding Seminar Nasional Integrated Farming System, Gorontalo 25-26 November 2018

"Pembangunan Pertanian-Peternakan-Perikanan Berkelanjutan Menuju Ketahanan Pangan Nasional"

\title{
DAMPAK PROGRAM PERCEPATAN PENINGKATAN TATA GUNA AIR IRIGASI (P3- TGAI) SECARA PARTISIPATIF TERHADAP KETAHANAN PANGAN NASIONAL DI KABUPATEN BONE BOLANGO
}

\author{
Merita Ayu Indrianti ${ }^{1}$, Karmila Olii ${ }^{2}$ \\ ${ }^{1}$ Fakultas Ilmu-Ilmu Pertanian, Universitas Muhammadiyah Gorontalo \\ ${ }^{2}$ Fakultas Ilmu-Ilmu Pertanian, Universitas Muhammadiyah Gorontalo \\ Email Untuk Korespondensi: ayu_sutarto@yahoo.co.id
}

\begin{abstract}
ABSTRAK
Sarana irigasi merupakan faktor penting dalam usaha tani khususnya tanaman pangan. Sistem irigasi merupakan tulang punggung ketahanan pangan keluarga yang bermuara pada ketahanan pangan tingkat nasional. Penelitian dilakukan di Kabupaten Bone Bolango. Tujuan penelitian; 1) mengetahui tingkat partisipasi petani pemakai air dalam pelaksanaan program P3-TGAI, 2) hubungan antara faktor-faktor yang mempengaruhi tingkat partisipasi petani, 3) dampak program P3-TGAI secara partisipatif. Penelitian menggunakan metode survei serta analisis deskriptif dan korelasi rank spearman. Hasil penelitian menunjukkan: 1) Tingkat partisipasi petani pada tahap perencanaan mencapai skor 58,86\% kategori selalu, pada tahap pelaksanaan mencapai skor 80,14\% kategori selalu dan tahap evaluasi mencapai skor 77,30\% kategori sering. 2) Faktor internal: tingkat pendidikan $\left(0,240^{* *}\right)$ berhubungan nyata pada tahap perencanaan dengan taraf signifikan 0,01 . Faktor eksternal: penyuluhan berhubungan nyata pada tahap perencanaan dan tahap evaluasi $\left(0,352^{* *}\right)$ dan $\left(-0,254^{* *}\right)$ taraf signifikan 0,01 . - pembinaan berhubungan nyata pada tahap perencanaan $\left(0,237^{* *}\right)$ dengan taraf signifikan 0,01. 3) Program percepatan peningkatan tata guna air irigasi memberikan dampak baik kepada petani dengan nilai persentase $(63,82 \%)$, karena dengan adanya program ini dapat mengatasi kesulitan air yang dibutuhkan oleh petani.

Kata Kunci: Program Percepatan Peningkatan Tata Guna Air Irigasi(P3-TGAI), Ketahanan Pangan, Tingkat Partisipasi, Kabupaten Bone Bolango
\end{abstract}

\section{PENDAHULUAN}

Pembangunan pertanian di Indonesia menjadi upaya yang harus di tingkatkan agar pertanian di Indonesia lebih maju. Salah satu upaya peningkatan pertanian adalah meningkatkan irigasi agar petani dapat meningkatkan produksi pertanian. Menurut Wahyudi (2014) irigasi adalah usaha penyediaan, pengaturan dan pembuangan air irigasi untuk menunjang pertanian yang jenisnya meliputi irigasi permukaan, irigasi bawah tanah, irigasi pompa dan irigasi tampak. Sedangkan sistem irigasi terdiri dari prasarana irigasi, air irigasi, manajemen irigasi, kelembagaan pengelolaan irigasi dan sumber daya manusia.

Program Percepatan Peningkatan Tata Guna Air Irigasi (P3-TGAI) merupakan program pemerintah yang diberikan kepada masyarakat agar pembangunan pertanian meningkat. Agar program terlaksana dengan baik maka di butuhkan suatu pola manajerial dalam pelaksanaan, dengan maksud agar hasil pelaksanaan program dapat dirasakan dan dinikmati manfaatnya oleh masyarakat. Salah satu hal yang dibutuhkan adalah kesadaran dan partisipasi aktif dari seluruh masyarakat dalam menunjang suksesnya pelaksanaan Program Percepatan Peningkatan Tata Guna Air Irigasi (P3TGAI). Selain itu juga pemerintah untuk mengarahkan serta membimbing petani untuk bersama-sama melaksanakan Program Percepatan Peningkatan Tata Guna Air Irigasi (P3-TGAI) secara partisipasi.

Partisipasi petani merupakan modal utama dalam upaya mencapai sasaran program. Keberhasilan dalam pencapaian sasaran pelaksanaan program percepatan peningkatan tata guna air irigasi (P3-TGAI) bukan semata-mata didasarkan pada kemampuan pemerintah, tetapi juga berkaitan dengan upaya mewujudkan kemampuan masyarakat untuk berpartisipasi dalam pelaksanaan program. Adanya partisipasi masyarakat akan mengimbangi kemampuan pemerintah dalam pencapaian pelaksanaan program tersebut.

Partisipatif harus dimulai dengan masyarakat sebagai manusia yang memiliki aspirasi dan paling mengetahui tentang kebutuhannya. Petani adalah pelaku utama dalam pelaksanaan program dan pemerintah harus memposisikan diri sebagai fasilitator untuk menciptakan suasana yang menunjang kegiatan masyarakat yang diharapkan dapat mendukung program percepatan peningkatan tata guna air irigasi (P3-TGAI) melalui partisipatif. 
Prosiding Seminar Nasional Integrated Farming System, Gorontalo 25-26 November 2018

"Pembangunan Pertanian-Peternakan-Perikanan Berkelanjutan Menuju Ketahanan Pangan Nasional"

Kabupaten Bone Bolango merupakan salah satu kabupaten yang ada di provinsi Gorontalo. Kabupaten Bone Bolango adalah kabupaten yang terdiri dari 18 kecamatan menjadi sasaran pelaksanaan Program Percepatan Peningkatan tata Guna Air Irigasi (P3-TGAI).

\section{METODOLOGI}

Lokasi penelitian yaitu Kabupaten Bone Bolango dengan sasaran penelitian yaitu petani lahan basah dan lahan kering. Lokasi tersebut dipilih karena Kabupaten Bone Bolango yang memanfaatkan irigasi dan melaksanakan program percepatan peningkatan tata guna air irigasi (P3-TGAI) secara partisipatif. Waktu pelaksanaan penelitian dari bulan April sampai Juni 2018.

Penelitian ini terdapat dua variabel yaitu variabel bebas (dependent) dan variabel terikat (independent). Variabel bebas dalam penelitian ini adalah faktor internal dan ekternal dan variabel terikat adalah tingkat partisipasi petani.

Metode penelitian yang digunakan dalam penelitian ini adalah metode penelitian deskripsi karena adanya variabel-variabel yang akan ditelaah hubungannya serta tujuan untuk menyajikan gambaran secara terstruktur, faktual dan akurat mengenai fakta-fakta serta hubungan variabel yang diteliti. Menurut Noor (2010) Penelitian deskripsi adalah bertujuan untuk mendeskripsikan sifat atau karakteristik dari suatu gejala, peristiwa, kejadian yang terjadi saat ini. Dalam metode ini akan diperoleh deskripsi tentang dampak program P3-TGAI terhadap petani dan tingkat partisipasi petani serta hubungan yang terjadi antara faktor internal dan eksternal.

Analisis data yang digunakan dalam penelitian ini terdiri dari analisis deskriftif, analisis partisipasi dan analisis hubungan. Ketiga analisis ini akan menjelaskan masalah dan kondisi mengenai tingkat partisipasi petani dalam pelaksanaan program P3-TGAI.

Menganalisis tingkat partisipasi petani dalam pelaksanaan program P3-TGAI digunakan analisis skala dengan menggunakan interval kelas yang dikategorikan ke dalam bentuk partisipasi selalu, sering, kadang-kadang, jarang, tidak pernah. Skala selalu di beri angka 5, sering di beri angka 4, kadang-kadang di beri angka 3, jarang di beri angka 2 dan tidak pernah di beri angka 1 . Dalam menentukan interval kelasnya digunakan rumus (Nasir, 2013), yaitu:

$$
k=\frac{R}{I}
$$

Dimana : $\mathrm{k}=$ interval kelas, $\mathrm{I}=$ jumlah interval kelas, $\mathrm{R}=$ range

Teknik analisis yang digunakan dalam penelitian ini adalah teknik kuantitatif dengan uji statistik yaitu dengan rumus korelasi spearman rank yang digunakan mengkaji hubungan antara faktor-faktor yang mempengaruhi partisipasi. Pengolahan data menggunakan bantuan SPSS (Statistical Product and Service Solutions). Analisis statistik spearman rank sangat tepat digunakan untuk mengetahui hubungan korelasi yang terkait dengan partisipasi. Persamaan analisis tersebut adalah sebagai berikut:

$$
r_{s}=1-\frac{6 \sum \mathrm{d}^{2}}{\mathrm{n}\left(\mathrm{n}^{2}-1\right)}
$$

Dimana : rs $=$ Nilai korelasi Sperman Rank, yaitu koefisien korelasi peringkat berdasarkan ukuran bagi hubungan antara variabel terikat $\mathbf{Y}$ (partisipasi petani) dan variabel bebas $\mathbf{X}$ (faktor internal dan ekternal); $\mathrm{d}^{2}=$ selisih antara peringkat $\mathbf{X}$ dan $\mathbf{Y} ; \mathrm{n}=$ jumlah pasangan data

Kaidah pengambilan keputusan sebagai berikut:

1. Jika nilai signifikansi $<\alpha(0,01)$, maka H0 ditolak, H1 diterima, artinya terdapat hubungan antara kedua variabel yang diuji.

2. Jika nilai signifikansi $>\alpha(0,01)$, maka $\mathrm{H} 0$ diterima, H1 ditolak, artinya tidak terdapat hubungan antara kedua variabel yang diuji.

\section{HASIL DAN PEMBAHASAN}

Partisipasi petani dalam pelaksanaan Program Percepatan Peningkatan Tata Guna Air Irigasi (P3-TGAI) pada penelitian ini merupakan keikutsertaan petani dalam seluruh tahapan kegiatan. Program Percepatan Peningkatan Tata Guna Air Irigasi (P3-TGAI) meliputi tiga tahapaan partisipasi yaitu tahapan perencanaan, tahapan pelaksanaan dan tahapan evaluasi. Tingkat partisipasi petani di Kabupaten Bone Bolango dapat dilihat pada tabel 1. 
Prosiding Seminar Nasional Integrated Farming System, Gorontalo 25-26 November 2018 "Pembangunan Pertanian-Peternakan-Perikanan Berkelanjutan Menuju Ketahanan Pangan Nasional"

Bentuk-bentuk partisipasi ini dalam kegiatan pelaksanaan tentunyamemerlukan prasyarat, salah satunya adalah unsur kesukarelaan dalam melakukan peran atau partisispasi dalam keterlibatan terhadap suatu masalah yangmemerlukan peran serta dari berbagai kalangan disekelilingnya untuk dapat mencapai tujuan. Proses peran serta atau partisipasi menggambarkan keterlibatan personal dalam bentuk: (1) proses pengambilan keputusan; (2)menentukan kebutuhan yang diinginkan; dan (3) menunjukan dan mewujudkantujuan dan prioritas yang ingin dicapai (Sastropoetro, 1998 dalam Melis 2016).

Tabel 1. Partisipasi Petani Dalam Pelaksanaan Program P3-TGAI

\begin{tabular}{|c|c|c|c|}
\hline Tingkat Partisipasi petani & Kategori & Jumlah & Presentase (\%) \\
\hline \multirow{5}{*}{$\begin{array}{l}\text { Tingkat partisipasi pada tahap } \\
\text { perencanaan program P3-TGAI }\end{array}$} & Tidak pernah (3-11) & 3 & 2,13 \\
\hline & Jarang (12-23) & 5 & 3,55 \\
\hline & Kadang-kadang (24-35) & 25 & 17,73 \\
\hline & Sering (36-47) & 25 & 17,73 \\
\hline & Selalu(>48) & 83 & 58,86 \\
\hline \multicolumn{2}{|c|}{ Jumlah } & 141 & 100 \\
\hline \multirow{5}{*}{$\begin{array}{l}\text { Tingkat partisipasi pada tahap } \\
\text { pelaksanaan program P3-TGAI }\end{array}$} & Tidak pernah $(0-11)$ & 4 & 2,84 \\
\hline & Jarang (12-23) & 0 & 0 \\
\hline & Kadang-kadang (24-35) & 24 & 17,02 \\
\hline & Sering (36-47) & 0 & 0 \\
\hline & Selalu (>48) & 113 & 80,14 \\
\hline \multicolumn{2}{|c|}{ Jumlah } & 141 & 100 \\
\hline \multirow{5}{*}{$\begin{array}{l}\text { Tingkat partisipasi pada tahap } \\
\text { evaluasi kegiatan pelaksanaan } \\
\text { program P3-TGAI }\end{array}$} & Tidak pernah (2-38) & 32 & 22,70 \\
\hline & Jarang (39-85) & 0 & 0 \\
\hline & Kadang-kadang (86-133) & 0 & 0 \\
\hline & Sering (134-181) & 109 & 77,30 \\
\hline & Selalu (>182) & 0 & 0 \\
\hline \multicolumn{2}{|c|}{ Jumlah } & 141 & 100 \\
\hline
\end{tabular}

Sumber: Olahan data primer (2018)

Faktor-faktor yang diduga berhubungan keaktifan petani berpartisipasi dalam pelaksanaan program P3-TGAI yaitu faktor internal terdiri dari umur, tingkat pendidikan, jumlah tanggungan keluarga, luas lahan, pengalaman bertani dan pendapatan. Hasil analisis uji korelasi rank spearmandapat dilihat pada tabel 2.

Tabel 2. Analisis Uji Korelasi Rank Spearman Faktor Internal dengan Tingkat Partisipasi Pelaksanaan Program P3-TGAI

\begin{tabular}{lccc}
\hline \multirow{2}{*}{ Faktor Internal } & \multicolumn{3}{c}{ Tingkat partisipasi } \\
\cline { 2 - 4 } & $\begin{array}{c}\text { Perencanaan } \\
\text { pelaksanaan } \\
\text { program P3- } \\
\text { TGAI }\end{array}$ & $\begin{array}{c}\text { Pelaksanaan } \\
\text { progam P3- } \\
\text { TGAI }\end{array}$ & $\begin{array}{c}\text { Evaluasi } \\
\text { pelaksanaan } \\
\text { program P3- } \\
\text { TGAI }\end{array}$ \\
\hline Umur & 0,128 & $-0,099$ & $-0,111$ \\
Tingkat Pendidikan & $0,240^{* *}$ & 0,097 & $-0,062$ \\
Jumlah Tanggungan Keluarga & 0,087 & $-0,038$ & $-0,056$ \\
Luas Lahan & 0,068 & 0,114 & $-0,079$ \\
Pengalaman Bertani & 0,117 & 0,120 & $-0,143$ \\
Pendapatan & 0,025 & 0,079 & $-0,053$ \\
\hline
\end{tabular}

Keterangan: $\mathrm{n}=141$, nilai signifikan $a=0.01$

Sumber: Olahan data primer (2018) 
Prosiding Seminar Nasional Integrated Farming System, Gorontalo 25-26 November 2018

"Pembangunan Pertanian-Peternakan-Perikanan Berkelanjutan Menuju Ketahanan Pangan Nasional"

Faktor eksternal adalah faktor yang berasal dari luar yang berhubungan dengan tingkat partisipasi petani dalam pelaksanaan program ini. Faktor eksternal terdiri dari komunikasi antara petani dan pengelola program, penyuluhan, sosialisasi, pendampingan dan pembinaan, kemudian di analisis dengan korelasi rank spearman untuk melihat hubungan (Tabel 3).

Tabel 3. Analisis Uji Korelasi Rank Spearman Faktor Ekternal Dengan Tingkat Partisipasi Pelaksanaan Program P3-TGAI

\begin{tabular}{lccc}
\hline \multirow{2}{*}{ Faktor eksternal } & \multicolumn{3}{c}{ Tingkat partisipasi } \\
\cline { 2 - 4 } & $\begin{array}{c}\text { Perencanaan } \\
\text { pelaksanaan } \\
\text { program P3- } \\
\text { TGAI }\end{array}$ & $\begin{array}{c}\text { Pelaksanaan } \\
\text { progam P3- } \\
\text { TGAI }\end{array}$ & $\begin{array}{c}\text { Evaluasi } \\
\text { pelaksanaan } \\
\text { program P3- } \\
\text { TGAI }\end{array}$ \\
\hline $\begin{array}{l}\text { Komunikasi antara petani dan pengelola } \\
\text { program P3-TGAI }\end{array}$ & 0,118 & 0,093 & 0,066 \\
Penyuluhan & $0,352^{* *}$ & $-0,048$ & $-0,254^{* *}$ \\
Sosialisasi & $0,176^{*}$ & $-0,076$ & $-0,148$ \\
Pendampingan & 0,025 & $-0,062$ & 0,140 \\
Pembinaan & $-0,237^{* *}$ & 0,013 & $-0,041$ \\
\hline
\end{tabular}

Keterangan: $\mathrm{n}=141$, nilai signifikan $a=0.01$

Sumber: Olahan data primer (2018)

Percepatan peningkatan tata guna air irigasi (P3-TGAI) merupakan program yang dilaksanakan untuk memperbaiki jaringan irigasi yang ada di Kabupaten Bone Bolango. Program ini menjadi sarana baik apabila dilakukan pemeliharan dengan baik. Hal tersebut jika petani melaksanakan program ini dengan efektif maka akan memenuhi kebutuhan air dan dapat meningkatkan produksi padi.

Berdasarkan hasil wawancara bahwa dari 141 petani 90 orang $(63,82 \%)$ mengatakan dengan adanya program percepatan peningkatan tata guna air irigasi (P3-TGAI) ini memberikan dampak yang baik untuk petani dalam memenuhi kebutuhan air jika terjadi musim kemarau, dan mengatasi masalah yang sering terjadi dalam proses penanaman. Sedangkan 51 orang $(36,17 \%)$ mengatakan bahwa program ini tidak memberikan dampak baik karena program ini dianggap hanya sebatas program yang diberikan oleh pemerintah namun tidak dimanfaatkan oleh petani.

\section{KESIMPULAN}

Tingkat partisipasi petani dalam pelaksanaan program P3-TGAI di Kabupaten Bone Bolango dilihat dari tiga tahap partisipasi yaitu tahap perencanaan mencapai skor 58,86\% pada kategori selalu, sedangkan pada tahap pelaksanaan mencapai skor $80,14 \%$ pada kategori selalu dan pada tahap evaluasi mencapai skor $77,30 \%$ pada kategori sering. Faktor internal: tingkat pendidikan $(0,240 * *)$ berhubungan nyata pada tahap perencanaan dengan taraf signifikan 0,01. Faktor eksternal: penyuluhan berhubungan nyata pada tahap perencanaan dan tahap evaluasi dengan nilai $(0,352 * *)$ dan $(-0,254 * *)$ dengan taraf signifikan 0,01 - pembinaan berhubungan nyata pada tahap perencanaan ($0,237 * *)$ dengan taraf signifikan 0,01 . Program percepatan peningkatan tata guna air irigasi (P3TGAI) memberikan dampak yang baik dengan nilai persentase $(63,82 \%)$ kepada petani, karena dengan adanya program ini dapat mengatasi masalah yang sering terjadi salah satunya kekurangan air pada saat melakukan budidaya.

\section{REFERENSI}

Melis. 2016. Analisis Partisipasi Masyarakat Dalam Pembangunan Desa (Studi Di Desa Wawolesea Kecamatan Lasolo Kabupaten Konawe Utara). Skripsi. Universitas Halu Oleo.

Nasir, M. 2013. Metode Penelitian. Ghalia Indonesia. Bogor.

Noor, J. 2010. Metodologi Penelitian Skripsi, Tesis, Disertasi dan Karya Ilmiah. Prenada Media Group. Jakarta.

Wahyudi. 2014. Strategi Peningkatan Kinerja Gabungan Perkumpulan Petani Pemakai Air (Gp3a) Di Kabupaten Bogor. Skripsi. Institut Pertanian Bogor. 